\title{
Pensar la traducción como obra de arte
}

\author{
Aline Celia Tonon Parra
}

\begin{abstract}
Resumo
O seguinte trabalho foi apresentado para avaliação final de curso realizado em intercâmbio na Universidad de Buenos Aires em maio de 2016. O curso - que se chamava "Filosofía de la Traducción" e cujo professor responsável era Horácio Gonzales - incentivava a discussão da possibilidade de pensar em um gênero artístico a partir das linguagens de outros gêneros e entender como se dá o processo de uma nova época ou uma forma original de sensibilidade antes desconhecida a partir de um descobrimento artístico. Tradução era pensada ali como uma prática de diversas interpretações possíveis para o fazer e entender artístico e filosófico. Seria possível então pensar o próprio ato de traduzir como uma criação artística? A partir da leitura de vários autores que permeiam o assunto de maneira mais teórica - como Benjamin e Haroldo de Campos - e também de autores que abordam a questão através de uma concepção mais poética do tema - como é o caso de Cesar Aira e Jorge Luis Borges -, este ensaio procura abrir novas possibilidades para o entendimento da tradução como categoria estética.
\end{abstract}

Palavras-chave: tradução; forma; arte; língua

\section{Resumen}

El siguiente trabajo ha sido presentado para evaluación final del curso realizado en intercambio en la Universidad de Buenos Aires en mayo de 2016. El curso -que se llamó "Filosofía de la Traducción" y cuyo profesor responsable era Horácio Gonzales- incentivaba la discusión de la posibilidad de pensarse un género artístico a partir de los lenguajes de otros géneros y entender cómo se da el proceso de una nueva época o una forma original de sensibilidad antes desconocida a partir de un descubrimiento artístico. Traducción era pensada allí como una práctica de diversas interpretaciones posibles para el hacer y entender artístico y filosófico. ¿Sería posible pensar el propio acto de traducir como una creación artística? A partir de la lectura de diversos autores que permean el tema de manera más teórica -como Benjamin y Haroldo de Campos- y también de autores que lo abordan desde una concepción más poética del tema -como es el caso de Cesar Aira y Jorge Luis Borges-, este ensayo busca abrir nuevas posibilidades para el entendimiento de la traducción como categoría estética.

Palabras clave: traducción; forma; arte; lengua. 
Quizás sea posible pensar la traducción como forma de arte, lo que sugiere pensar en la traducción como forma de creación a partir de un primero elemento. No como en el caso de producir una película a partir de un libro. Esa no sería una traducción, sino una transposición del arte a otro género. La cuestión aquí es averiguar específicamente un texto escrito y si su traducción a otra lengua implica algún hacer artístico de alguna manera. Sin embargo, no se puede dejar de considerar: ¿una traducción de un texto en verso que se pasa a otra lengua en prosa no es también un cambio de género?

Son muchos los cuestionamientos y es verdad que la traducción ha sido tema de reflexión por parte de innúmeros estudiosos que discuten sus posibilidades y límites, sus consecuencias y despliegues en el campo poético y literario. Pero no solo a los investigadores y teóricos ese tema afecta, sino que diversos escritores, para los cuales la traducción muchas veces es parte integrante de su proceso de trabajo -ya sea por actuaren también como traductores, ya sea por encontrar traducidas muchas de sus propias obras para otros idiomastambién reflexionaron y escribieron sobre ello.

Ese es el caso de Cesar Aira, quien, en un pequeño ensayo sobre la traducción, plantea una cuestión hipotética y llega a la conclusión de que en la microscopia de la escritura se producen tantos cambios que necesariamente se acaba por transformar el original, de tal manera que se cría otro texto: “(...) Ahí yo, traductor (pero todo esto es un problema imaginario), adoptaría una solución radical (...) Poco a poco se iría transformando en una novela mía, y no sé si podría seguir tratándose de una traducción.”(AIRA, 2014, p. 9).

En otra reflexión sobre la traducción, publicada en la revista Xul, César Aira compara la traducción a un mito: si de verdad existe, la traducción es un dispositivo propulsor de singularidades y, por lo tanto, su ritual es la literatura. Su argumento se centra en la idea de que la traducción se refiere a todo acto de pensamiento y aprendizaje y nada puede garantizar que se pueda encontrar en ella vestigios fácilmente identificables del texto o imagen antecesores. $\mathrm{Si}$ traducir indica cambiar de un código -aquí entendido como lengua- a otro, también significa saltar de un universo a otro.

A partir de solo esos dos textos de Aira se puede intuir que para él, la posición de algunos artistas, en la contemporaneidad, es adversa a la traducción, porque los estímulos plásticos de la realidad no son convertidos en un lenguaje unificado, sino que permanecen en estado bruto. No hay representación -y para entender eso basta recordar a Duchamp, quien cuestionaba justamente el sentido del arte y realidad. La traducción apenas genera interés, según Aira, cuando existe un cambio de tonalidad en el código. Sin eso, es un simple pasatiempo. El autor incluso empieza su texto de la revista $X u l$ con la afirmación categórica: "La traducción es la madre del estilo".(AIRA, 1982, p.7)

De manera general todo lo anterior implica concluir que el traductor puede ser 
simbolizado como el ojo de un pueblo, de una cultura, que posibilita la lectura de los textos de otras culturas y a la vez, por medio de sus elecciones, lanza una mirada, de sujeto inserido en un contexto histórico y social, sobre el contacto entre lenguas y culturas diferentes.

La mirada del traductor incluye el conjunto de parámetros lingüísticos, culturales e históricos que inciden en su modo de sentir, actuar y pensar que a su vez orientan su proyecto de traducción, ya que no se traduce da la misma manera en un mismo contexto histórico y social de otros traductores. Asimismo, si se hace la experiencia de dar a dos personas un mismo texto en un mismo momento fácilmente se podría percibir que cada una traduciría el texto de maneras diferentes y eso es porque también entra en juego el subjetivismo, eso es, la característica personal de cada individuo de interpretar una información, hacerla pasar por su individualidad y luego extraerla de sí de una manera que contiene un poco de él.

Pero también el proceso de traducción es una mirada sobre el otro. No una simple copia o transferencia de significados, sino un cambio de miradas entre individuos distintos, culturas distintas, textos distintos, constituyendo, necesariamente, un acto de interpretación y también de cuestionamientos.

Es posible también pensar el traductor como un mediador entre el autor del texto original y el texto meta que, para tanto, se plantea entre dos universos de discursos al reconstruir lo que fue enunciado en otro idioma, dirigiéndose al público al cual el autor no se puede dirigir directamente. Queda claro entonces, que para autores como Aira la traducción aparece como un asunto relacionado al hacer literario y no apenas como un proceso técnico de transposición idiomática.

Esa idea puede ser conjugada a lo que propone Walter Benjamin en el ensayo "La tarea del traductor" que debido a su complejidad y audacia, desde su publicación ha causado muchas discusiones y lecturas que llegan a ser completamente divergentes. Paul de Man, por ejemplo, afirma que el texto de Benjamin es imposible de traducir, y explica esa afirmación señalando y confrontando algunas traducciones del proprio ensayo de Benjamin como la de Harry Zohn para el inglés y la de Maurice de Gandillac para el francés, en las cuales hay trechos traducidos con sentidos totalmente opuestos entre sí.

Defiende Paul de Man, en un análisis hecho a partir del texto de Benjamin, que el traductor está perdido desde el inicio ya que cualquier traducción siempre es inferior comparada al original. A dicha concepción tradicional, sin embargo, hay en oposición un pensamiento de Jorge Luis Borges, que aparece en "Las Versiones Homéricas", en que el autor dice que la recombinación de elementos no es obligatoriamente inferior al original y que la creencia en la inferioridad de las traducciones procede de la experiencia de la repetición.

Avanzando un poco en ese autor, es posible apreciar en el texto de Borges algunas reflexiones sobre la validad e importancia de las traducciones para la literatura y queda claro como en su obra la traducción nunca ocupa un lugar secundario sino que es concebido como 
uno de los muchos géneros de la literatura, tan importante como los demás. Borges indica tal importancia de las traducciones no apenas para la circulación de textos fundamentales a la biblioteca universal sino también por elucidaren aspectos de la creación literaria que no se dejan vislumbrar en otras situaciones:

Ningún problema tan consustancial con las letras y con su modesto misterio como el
que propone una traducción. Un olvido animado por la vanidad, el temor de confesar
procesos mentales que adivinamos peligrosamente comunes, el conato de mantener
intacta y central una reserva incalculable de sombra, velan las tales escrituras directas.
La traducción, en cambio, parece destinada a ilustrar la discusión estética. El modelo
propuesto a su imitación es un texto visible, no un laberinto inestimable de proyectos
pretéritos o la acatada tentación momentánea de una facilidad. (BORGES, 2012, p. 1)

Problemas técnicos de escritura, procesos de creación, bien como la génesis del texto y la discusión estética que marca la literatura y que, muchas veces, se encuentra oscurecida en la observación de las estrategias poéticas de construcción de narrativas, son perceptibles y se pueden analizar a partir de la traducción. Ella es la que posibilita este acto. Así, Borges reafirma la validad de la traducción en el campo literario: pese a todas las dificultades inherentes al proceso traductor, lo que vale son las repercusiones de lo verbal y sus muchas posibilidades de irradiación.

De todos modos, volviendo a Benjamin, la idea central de su ensayo es defender que la tarea del traductor no es dar sentido comunicacional al objeto artístico, sino que se trata de dar forma, libertándose de la obligatoriedad de la transmisión de sentido referencial, de transferir contenido comunicacional. Así, puede el traductor centrarse en la manera como transferir el contenido que ya fuera organizado por el original. Es a partir de la transmisión del contenido que la función del traductor permite buscar la complementariedad entre las intenciones de las lenguas.

Existe, para Benjamin, una diferencia clara entre la categoría de la cual pertenece una obra original y la categoría de la cual pertenece la traducción. En la primera, no se considera tanto el destinatario como sí se lo hace en la categoría en la que se insiere la traducción. Y eso se explica porque Benjamin parte de la idea de que lo que motiva una obra literaria no es la comunicación y afirma: "Ningún poema está dedicado al lector, ningún cuadro a quien lo contempla, ni sinfonía alguna a quienes la escuchan" (BENJAMIN, 1976, p. 128).

Así, según esa concepción -que puede ser muy bien cuestionada y efectivamente ha sido-, la traducción se encuentra en la misma categoría que la teoría literaria o la historia, pues todas tienen la característica de ser secundarias en relación a una primera. Deriva la teoría literaria de la poesía, como la historia de los actos y, así como sucede con la traducción, no se asemejan con aquello de lo cual derivan. Son otra clase aunque son todas intralingüísticas y se relacionan con aquello que en el original pertenece al lenguaje. Sin duda es un concepto 
interesante, pero quizás demasiado impositivo y categórico. ¿Entonces no habría más matices para pensar la traducción como una especie de creación artística?

Otra idea, la de la imposibilidad de la traducción, que suena a una concepción romántica, humboldtiana, de que diferentes lenguas remetan a diferentes percepciones de la realidad, de manera que no es posible alterar la expresión lingüística sin alterar el contenido, es retomada por diversos autores. Sin embargo parece ser que en la contemporaneidad tales cuestiones están direccionadas para el concepto de fidelidad, que implica pensar el traductor a veces como substituto del autor, a veces como intérprete.

La multiplicidad de posibilidades de utilización de la lengua y su vínculo con la cultura determinan la imposibilidad de la traducción literal, ya que la creación textual exige elecciones, opciones, así como lo es la traducción. Ello implica el reconocimiento de que cualquier traducción siempre será la creación de otro texto, lingüística y culturalmente diverso del primero.

El termino transcriación parece dar cuenta de los problemas implicados en pensar la traducción. El traductor y escritor Haroldo de Campos entendía la transcriación principalmente como una postura de fidelidad. La traducción debe estar atenta al modo de construcción de un texto, a sus aspectos fono semánticos, a su configuración de significado. Esto es, una literalidad y una adherencia al signo, un abordaje opuesto a la traducción fiel al contenido y a la forma más superficial del original (métrica y rima). Según Campos, lo lingüístico, la "estructura intertextual" y el intracódigo constituyen el territorio de la transcriación. A partir de esa idea de fidelidad y equivalencia con el objeto traducido es que la traducción puede ser entendida como una obra de arte.

Está muy claro que la traducción de una obra literaria es una tarea que exige un esfuerzo más que intelectual, es un proceso creativo y cognitivo y no apenas un juego de cambio lexical. Traducir una obra literaria es recriarla en un otro idioma, pero sin destituirla de sus características originales, lo que requiere habilidad: es necesario acertar el tono, adaptar ciertas expresiones. Eso ya ha sido pensado al constatar que muchas traducciones han superado al original. El problema de la categoría estética de la traducción debe ser ampliado.

Sería entonces posible decir que la misma manera que el traductor encuentra dificultades para transponer la realidad de una lengua para la realidad de otra, ¿ese mismo movimiento es lo que necesita hacer el hombre al depararse con una obra de arte? Más que necesario, parece ser ese un movimiento inherente al ser humano frente a una obra artística. Es imprescindible entender la realidad de aquella obra para que esta tenga sentido en su propia realidad.

Y si el arte es una forma de comunicación, un lenguaje, y si toda comunicación presupone una dialéctica -en el sentido Bakhtiniano de que un hablante siempre construye el discurso teniendo en cuenta el interlocutor-, entonces el proceso de la traducción se asemeja al 
arte. Y de la misma manera que el receptor de la forma artística tiene que interiorizar el objeto artístico y entenderlo según su propia subjetividad, el traductor también debe captar un texto (que sería el objeto artístico) y transformarlo en su propia lengua según su propia subjetividad.

Por fin, una de las maneras de entender la traducción es como un juego de espejos. Si el objeto a ser traducido es pensado como una realidad que debe ser transpuesta, entonces se trata de una interpretación de un reflejo de la realidad, de una imagen, y la transformación de esta en otra. Una interpretación subjetiva de mundo es un reflejo y el espejo uma metáfora para ese juego. La traducción es un espejo responsable por la transformación de un reflejo en otro. Un reflejo de aquello que ya se constituye como tal si pensamos en la subjetividad como reflejo. Y citando a Aira, en una traducción no se pierde nada, “[...] Podemos vivir sin estilo, o con espejismos de estilo. Quizás sea mejor así.” (AIRA, 1982, p.8).

\section{BiBliograFÍA}

AIRA, César. Continuación de ideas diversas. Santiago de Chile: Ediciones Universidad Diego Portales, 2014.

AIRA, César. Encuesta: la traducción poética. In: XUL Signo viejo y nuevo. Buenos Aires, nº, ,ago. 1982, p. 7-8.

BENJAMIN, Walter. "La tarea del traductor". In: ANGELUS NOVUS. Madrid: Edhasa, 1976.

BORGES, Jorge Luis. Las versiones homéricas. Alicante: Biblioteca Virtual Miguel de Cervantes, 2012.

CAMPOS, Haroldo de. Metalinguagem e outras metas: ensaios de teoria e crítica literária. São Paulo: Perspectiva, 2010.

MAN, Paul de. "Conclusiones: La tarea del traductor de Walter Benjamin". In: LA RESISTENCIA A LA TEORIA. Visor, 1990. 